\title{
Calcium-Dependent Persistent Facilitation of Spike Backpropagation in the CA1 Pyramidal Neurons
}

\author{
Hiroshi Tsubokawa, ${ }^{1}$ Stefan Offermanns, ${ }^{4}$ Melvin Simon, ${ }^{4}$ and Masanobu Kano ${ }^{2,3}$ \\ ${ }^{1}$ National Institute for Physiological Sciences, Okazaki 444-8585, Japan, ${ }^{2}$ Core Research for Evolutional Science and \\ Technology, Japan Science Technology Corporation, Kawaguchi 332-0012, Japan, ${ }^{3}$ Department of Physiology, \\ Kanazawa University School of Medicine, Kanazawa 920-8640, Japan, and ${ }^{4}$ Division of Biology, California Institute of \\ Technology, Pasadena, California 91125
}

Sodium-dependent action potentials initiated near the soma are known to backpropagate over the dendrites of CA1 pyramidal neurons in an activity-dependent manner. Consequently, later spikes in a train have smaller amplitude when recorded in the apical dendrites. We found that depolarization and resultant $\mathrm{Ca}^{2+}$ influx into dendrites caused a persistent facilitation of spike backpropagation. Dendritic patch recordings were made from CA1 pyramidal neurons in mouse hippocampal slices under blockade of fast excitatory and inhibitory synaptic inputs. Trains of 10 backpropagating action potentials induced by antidromic stimulation showed a clear decrement in the amplitude of later spikes when recorded in the middle apical dendrites. After several depolarizing current pulses, the amplitude of later spikes increased persistently, and all spikes in a train became almost equal in size. BAPTA (10 mm) contained in the pipette or low- $\mathrm{Ca}^{2+}$ perfusing solution abolished this depolarization-induced facilitation, indicating that $\mathrm{Ca}^{2+}$ influx is required. This facilitation was present in $\mathrm{G} \alpha_{\mathrm{q}}$ knock-out mice that lack the previously reported muscarinic receptor-mediated enhancement of spike backpropagation. Therefore, these two forms of facilitation are clearly distinct in their intracellular mechanisms. Intracellular injection of either calmodulin binding domain $(100 \mu \mathrm{M})$ or $\mathrm{Ca}^{2+} /$ calmodulin-kinase II (CaMKII) inhibitor 281-301 (10 $\mu \mathrm{m})$ blocked the depolarization-induced facilitation. Bath application of a membrane-permeable CaMKII inhibitor KN-93 (10 $\mu \mathrm{M})$ also blocked the facilitation, but KN-92 $(10 \mu \mathrm{M})$, an inactive isomer of $\mathrm{KN}-93$, had no effect. These results suggest that increases in $\left[\mathrm{Ca}^{2+}\right]_{i}$ cause persistent facilitation of spike backpropagation in the apical dendrite of CA1 pyramidal neuron by CaMKII-dependent mechanisms.

Key words: hippocampus; pyramidal neuron; dendrite; action potential; backpropagation; $\mathrm{Ca}^{2+} /$ calmodulin-dependent protein kinase II; neuronal excitability; neural plasticity; intracellular signaling
Neuronal excitability is precisely regulated by a combination of various ionic channels, pumps, and transporters. Activities of these elements are modulated not only by extracellular factors but also by the intracellular metabotropic pathways. Of particular interest is modulation of dendritic properties, because dendrites are the primary locus of synaptic integration and plasticity (Johnston et al., 1996). It is known that sodium-dependent action potentials backpropagate from near the soma toward the apical dendrites of cortical pyramidal neurons (Stuart and Sakmann, 1994). These spikes are attenuated in an activity-dependent manner such that later spikes in a train have smaller amplitudes when recorded in the apical arbors (Turner et al., 1991; Callaway and Ross, 1995; Spruston et al., 1995). Although physiological significance of the backpropagating spikes is not clear, characteristics of dendritic spikes and the mechanisms underlying their modulation have been addressed in recent years (Johnston et al., 1999). A contribution of both slow $\mathrm{Na}^{+}$channel inactivation (Colbert et al., 1997; Jung et al., 1997) and activation of A type $\mathrm{K}^{+}$channels

\footnotetext{
Received Dec. 20, 1999; revised March 6, 2000; accepted March 24, 2000.

This work has been supported in part by grants from the Japanese Ministry of Education, Science, Sports, and Culture (to H.T. and M.K.), the Human Frontier Science Program (to M.K.), and by Special Coordination Funds for Promoting Science and Technology from the Science and Technology Agency (to H.T. and M.K.). We thank Dr. Joseph C. Callaway for helpful comments and discussion on this manuscript.

Correspondence should be addressed to Hiroshi Tsubokawa, National Institute for Physiological Sciences, Okazaki 444-8585, Japan. E-mail: hiroshi@nips.ac.jp. Copyright (C) 2000 Society for Neuroscience $0270-6474 / 00 / 204878-07 \$ 15.00 / 0$
}

(Hoffman et al., 1997) have been shown in rat hippocampal CA1 neurons. The hyperpolarization-induced cation conductances $\left(I_{\mathrm{h}}\right.$ or $I_{\mathrm{q}}$ ) (Magee, 1998; Stuart and Spruston, 1998; Tsubokawa et al., 1999a), the persistent $\mathrm{Na}^{+}$conductance (Mittmann et al., 1997), and the G-protein-activated inwardly rectifying $\mathrm{K}^{+}$(Takigawa and Alzheimer, 1999) are predominantly distributed in the dendrites and are also suggested as possible contributors to the spike attenuation. We reported previously that activation of muscarinic acetylcholine receptors reduces the activity-dependent decrement of spike amplitude at the middle apical dendrites (Tsubokawa and Ross, 1997). Our pharmacological data strongly suggested that an M1 receptor-mediated pathway was mainly responsible because the M1-type antagonist pirenzepine almost completely blocked the muscarinic effects (Tsubokawa and Ross, 1997). The M1 receptor is considered to couple to Gq/11 and lead to activation of protein kinase C (PKC) (Hill, 1994). Muscarinic effects on the dendritic spike were deficient in CA1 neurons of mice lacking the $\alpha$ subunit of the heterotrimeric G-protein $\mathrm{G}_{\mathrm{q}}$ $\left(\mathrm{G} \alpha_{\mathrm{q}}\right)$ (Tsubokawa et al., 1998). Because PKC and protein kinase A (PKA) activation are reported to modulate $\mathrm{Na}^{+}$and/or $\mathrm{K}^{+}$ conductances in the dendrites (Colbert et al., 1997; Jung et al., 1997; Colbert and Johnston, 1998; Hoffman and Johnston, 1998), these G-protein-coupled systems may be involved in the dendritic spike modulation. Recently, Johnston et al. (1999) suggested an additional contribution of mitogen-activated protein kinase, because this kinase has been reported to regulate activities of the A-type $\mathrm{K}^{+}$channel (Adams et al., 1997). 
We report here a new type of backpropagating spike modulation. We found that large dendritic depolarizations and accompanying $\mathrm{Ca}^{2+}$ influx enhance spike backpropagation at the middle apical dendrites of CA1 pyramidal neurons in mouse hippocampal slices. This effect was present in mice lacking $\mathrm{G} \alpha_{\mathrm{q}}$ in which the muscarinic modulation was absent and was abolished by $\mathrm{Ca}^{2+} /$ calmodulin-dependent protein kinase II (CaMKII) inhibitors. Our results support a view that $\mathrm{Ca}^{2+}$-dependent but G-protein-independent mechanisms also contribute to the amplitude modulation.

\section{MATERIALS AND METHODS}

All experiments were performed according to the guidelines of the animal welfare committee of the National Institute for Physiological Sciences. Four- to 12-week-old inbred C57BL/6 or outbreed C57BL6x129sv $\left(\mathrm{G} \alpha_{\mathrm{q}}+/+, \mathrm{G} \alpha_{\mathrm{q}}+/-, \mathrm{G} \alpha_{\mathrm{q}}-/-\right)$ mice were deeply anesthetized with ether and decapitated. The brains were quickly removed and hemisected on filter paper moistened with cutting solution of the following composition (in $\mathrm{mM}$ ): 120 choline- $\mathrm{Cl}, 3 \mathrm{KCl}, 8 \mathrm{MgCl}_{2}, 1.25 \mathrm{NaH}_{2} \mathrm{PO}_{4}$, $26 \mathrm{NaHCO}_{3}$, and 20 glucose, equilibrated with $95 \% \mathrm{O}_{2}-5 \% \mathrm{CO}_{2}$. Brain tissues containing the hippocampi on both sides were dissected out and put in the cutting chamber filled with ice-cold cutting solution. These two blocks were sliced into $300 \mu \mathrm{m}$ sections transversely to their longitudinal axes by using a vibrating slicer (Campden Instruments, Lafayette, IN). The slices were immediately placed in a reservoir chamber filled with normal solution and incubated at $35^{\circ} \mathrm{C}$ for approximately a half hour and then maintained at room temperature. The normal recording solution was composed of (in mM): $125 \mathrm{NaCl}, 2.5 \mathrm{KCl}, 2 \mathrm{CaCl}_{2}, 2 \mathrm{MgCl}_{2}, 1.25$ $\mathrm{NaHPO}_{4}, 26 \mathrm{NaHCO}_{3}$, and 10 glucose, bubbled with a mixture of $95 \%$ $\mathrm{O}_{2}-5 \% \mathrm{CO}_{2}$, making the final $\mathrm{pH}$ 7.4. For recording, a single slice was transferred to a submerged chamber mounted on the stage of an upright microscope (BX50WI; Olympus Optical, Tokyo, Japan). The slice was superfused continuously with the normal solution regulated at $35^{\circ} \mathrm{C}$.

Electrical recordings were made from CA1 pyramidal neurons in slices using patch pipettes pulled from $1.5 \mathrm{~mm}$ outer diameter (o.d.), thickwalled glass tubing (1511 M; Friedrich \& Dimmock, Melville, NJ). The pipette solution contained (in $\mathrm{mM}$ ): $115 \mathrm{~K}$-gluconate, $10 \mathrm{KCl}, 10 \mathrm{NaCl}, 10$ HEPES, $2 \mathrm{Mg}$-ATP, and $0.3 \mathrm{GTP}$, $\mathrm{pH}$ adjusted to 7.3 with $\mathrm{KOH}$. Open resistance of the pipettes was 5-7 $\mathrm{M} \Omega$ for somatic recordings and 7-11 $\mathrm{M} \Omega$ for dendritic recordings. Whole-cell tight seals $(>5 \mathrm{G} \Omega$ ) were made on the soma or dendrite under visual control using a $40 \times$ waterimmersion lens. Capacitance was fully compensated by patch-clamp amplifier (Axopatch 1D; Axon Instruments, Foster City, CA). The ranges of series resistance we accepted for the somatic and the dendritic recordings were $10-15 \mathrm{M} \Omega$ and 22-30 $\mathrm{M} \Omega$, respectively. Bipolar stimulation electrodes constructed from thin tungsten wire $(50 \mu \mathrm{m}$ o.d.) were placed on the stratum oriens or the alveus in the CA2-C3 regions. Ten micromolar 6-cyano-7-nitroquinoxaline-2,3-dione (CNQX), $50 \mu \mathrm{M}$ D,L2-amino-5-phosphonovaleric acid (APV), and $10 \mu \mathrm{M}$ bicuculline methiodide (BMI) were always added in the perfusing solution to eliminate effects of fast synaptic inputs. Cells were identified as pyramidal neurons using both electrical and anatomical criteria. In some recordings, $50 \mu \mathrm{M}$ bis-fura- 2 was added to the pipette solution to measure changes in $\left[\mathrm{Ca}^{2+}\right] \mathrm{i}$ in response to depolarization. After allowing the dye to diff use into the cell, fluorescence images were recorded using a cooled CCD camera system (Merlin, Life Sciences, Hialeah, FL). The cell was excited every $32 \mathrm{msec}$ at $380 \pm 10 \mathrm{~nm}$ (exposure time of $1 \mathrm{msec}$ ) using a monochrometer, and fluorescence was measured at somatic region. Changes in $\left[\mathrm{Ca}^{2+}\right]_{\mathrm{i}}$ are presented as the spatial average of $\Delta F / F$ (percent), where $F$ is the fluorescence intensity at resting membrane potentials (corrected for background autofluorescence) and $\Delta F / F$ is the timedependent change in fluorescence (corrected for bleaching). Each record was smoothed by a 5-9 point moving average to reduce noise. BMI, CNQX, KN-92, and KN-93 were purchased from Research Biochemicals (Natick, MA). Calmodulin binding domain (CBD) and $\mathrm{Ca}^{2+} /$ calmodulin kinase II inhibitor 281-301 were obtained from CalbiochemNovabiochem (La Jolla, CA). APV, BAPTA, EGTA, and all other compounds were obtained from Sigma (St. Louis, MO).

\section{RESULTS}

In the presence of glutamate and $\mathrm{GABA}_{\mathrm{A}}$ receptor antagonists, trains of antidromic action potentials showed attenuation of spike
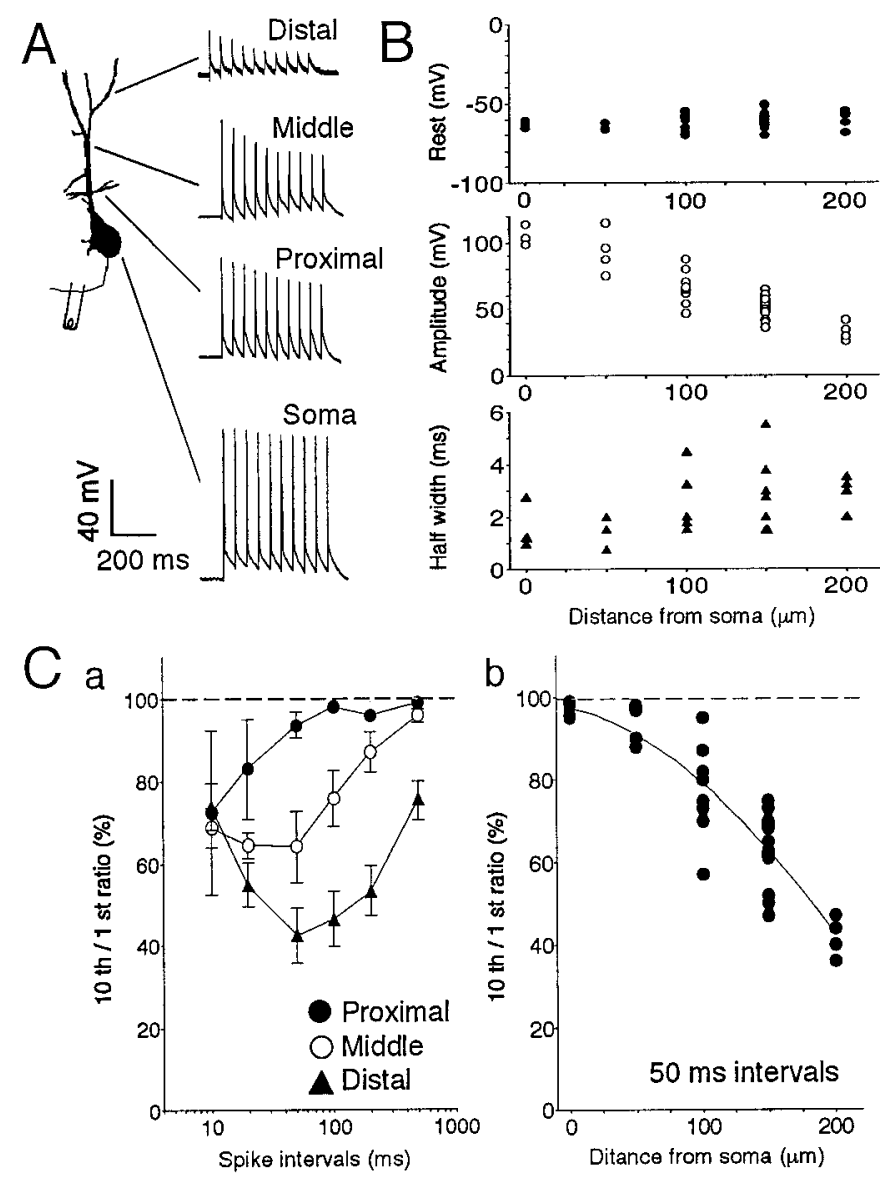

Figure 1. Action potentials recorded from the soma and the apical dendrites of mouse hippocampal pyramidal neurons. $A$, Representative traces of trains of 10 antidromic spikes $(20 \mathrm{~Hz})$ obtained from the soma and the proximal $(\sim 50 \mu \mathrm{m})$, middle $(\sim 100 \mu \mathrm{m})$, and distal $(\sim 200 \mu \mathrm{m})$ regions of the apical dendrites. $B$, Distributions of resting membrane potential (top), the amplitude (middle), and the half-width (bottom) of single spike as a function of distance from the soma. $C$, Decrement profiles shown as the ratio of the 10th spike amplitude over the 1st spike amplitude plotted against spike intervals $(a)$ and distance from the soma (b). Data were obtained from four somatic and 29 dendritic recordings in total.

height when recordings were made in the apical dendrite of a mouse CA1 neuron (Fig. 1). The resting membrane potential and basic properties of sodium-dependent action potentials recorded from the soma and several regions of the apical dendrites were investigated. The amplitude of single sodium spikes decreased, and the half-width increased, in accordance with distance from the soma (Fig. 1B). Profiles of the decrement indicated, as the 10 th/1st ratio of the spike amplitude showed, that the modulation depended on both the frequency (Fig. $1 \mathrm{Ca}$ ) and the distance from the soma (Fig. $1 \mathrm{Cb}$ ). The apical dendrite of the mouse pyramidal neuron used in the present study reached the molecular layer, which is $270-280 \mu \mathrm{m}$ from the soma. Therefore, we assumed that characteristics of active propagation in mouse CA1 dendrites were identical in those that have already been reported in the rat (Spruston et al., 1995; Tsubokawa and Ross, 1997), although absolute distance of recording site from the soma might be shorter than that of the rat.

When recordings were made on middle apical dendrites, depolarizing pulses injected through the recording pipettes caused a persistent decrease in the amplitude modulation of antidromically 

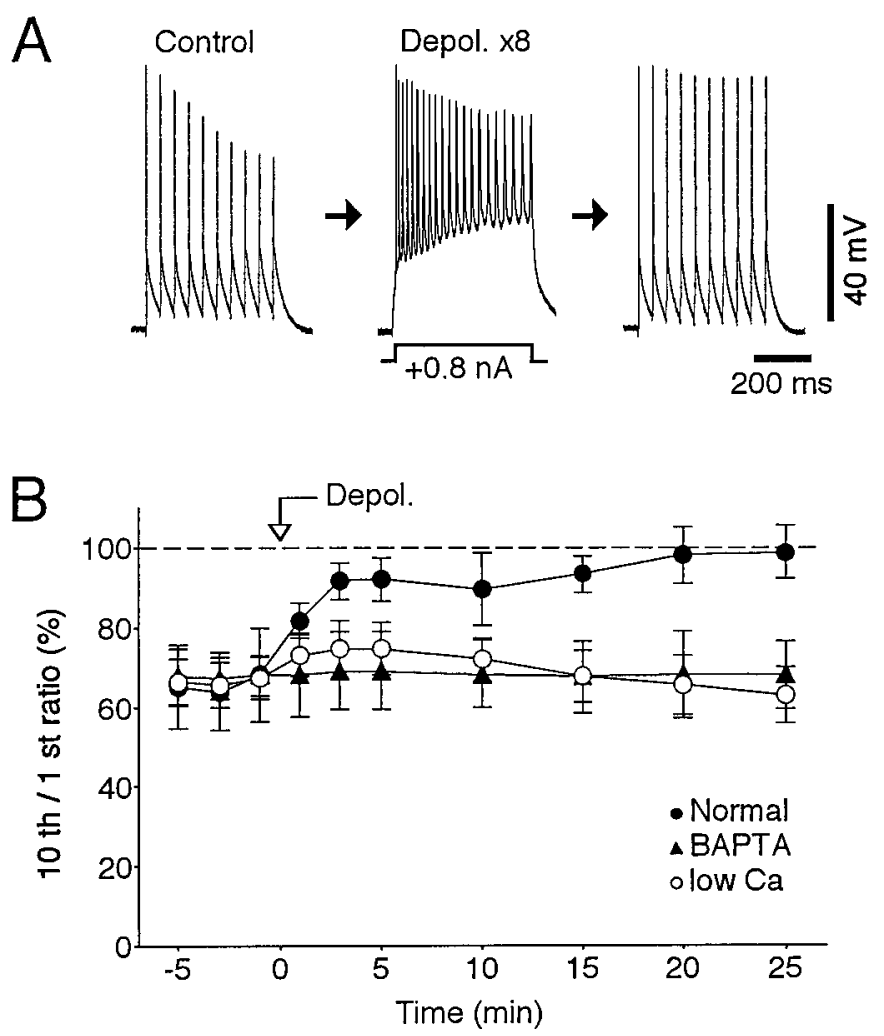

Figure 2. Persistent facilitation of spike backpropagation induced by depolarizing pulses. $A$, Records showing decrease in the modulation of spike amplitude induced by a train of depolarizing pulses $(+0.8 \mathrm{nA}, 500$ msec, 8 times with $10 \mathrm{sec}$ intervals). $B$, Time course of the change in decrement profiles in cells recorded with the standard pipette solution and normal $\mathrm{Ca}^{2+}$ containing $(2 \mathrm{mM}$ ) extracellular solution ( filled circles; $n=$ 9 ), in those with the pipette solution containing $10 \mathrm{~mm}$ BAPTA ( filled triangles; $n=6$ ), and in those with low extracellular $\mathrm{Ca}^{2+}$ (nominally 0 $\mathrm{mm}$ ) solution (open circles; $n=7$ ). Time 0 corresponds to the onset of first depolarizing pulse of the train.

activated spike trains. A typical record is shown in Figure $2 \mathrm{~A}$. The patch pipette was placed on an apical dendrite $100 \mu \mathrm{m}$ from the soma. After obtaining control profiles for the amplitude decrement by using 10 antidromic stimuli at $20 \mathrm{~Hz}$, eight depolarizing current pulses $(0.8 \mathrm{nA}, 500 \mathrm{msec})$ were applied in $10 \mathrm{sec}$ intervals. Bursts of sodium spikes were always observed during these depolarizing pulses. Within 5 min after the depolarizing pulses, amplitude modulation of antidromic spike train was abolished, and all spikes became equal in size to the first. Peak amplitude, width, and rise time of the first spike did not change significantly. Data obtained from nine different neurons were summarized in Figure $2 \mathrm{~B}$. In all neurons tested, the facilitation of spike backpropagation lasted for over $25 \mathrm{~min}$. Weaker conditioning depolarizing pulses with lower current intensities, shorter pulse durations, or longer pulse intervals could also induce facilitation of spike backpropagation. Moreover, trains of antidromic stimulation were effective to induce the facilitation in some neurons $(n=3)$. However, it took $10-30 \mathrm{~min}$ to establish the facilitation. To induce robust facilitation, we used five to eight repetitive depolarizing current injections $(0.6-0.8 \mathrm{nA}, 500 \mathrm{msec})$ as the conditioning stimuli in the later analysis.

We confirmed that the facilitation of spike backpropagation occurred in the presence of low concentration of BAPTA or EGTA $(<0.2 \mathrm{~mm})$. This indicates that the facilitation is not attributable to an artifact caused by washout of intrinsic $\mathrm{Ca}^{2+}$ buffers from the recorded neurons. We found that high concentration of BAPTA $(10 \mathrm{~mm})$ contained in the pipette $(n=6)$ or low-Ca ${ }^{2+}$ perfusing solution ( $\mathrm{Ca}$, nominally $0 \mathrm{mM} ; n=7$ ) abolished the effects of depolarization (Fig. 2B). Therefore, an increase in intracellular $\mathrm{Ca}^{2+}$ presumably caused by $\mathrm{Ca}^{2+}$ influx through the voltage-gated channels appears to play a key role in this effect.

We reported previously that pharmacological activation of muscarinic receptors could reduce frequency-dependent spike attenuation in the rat hippocampus (Tsubokawa and Ross, 1997). This effect appears to be mediated at least partly by PKC activation (Tsubokawa et al., 1999b). The effects were absent in CA1 neurons of mice lacking the $\alpha$ subunit of the heterotrimeric G-protein $\mathrm{G}_{\mathrm{q}}\left(\mathrm{G} \alpha_{\mathrm{q}}\right)$ (Tsubokawa et al., 1998) in which the M1
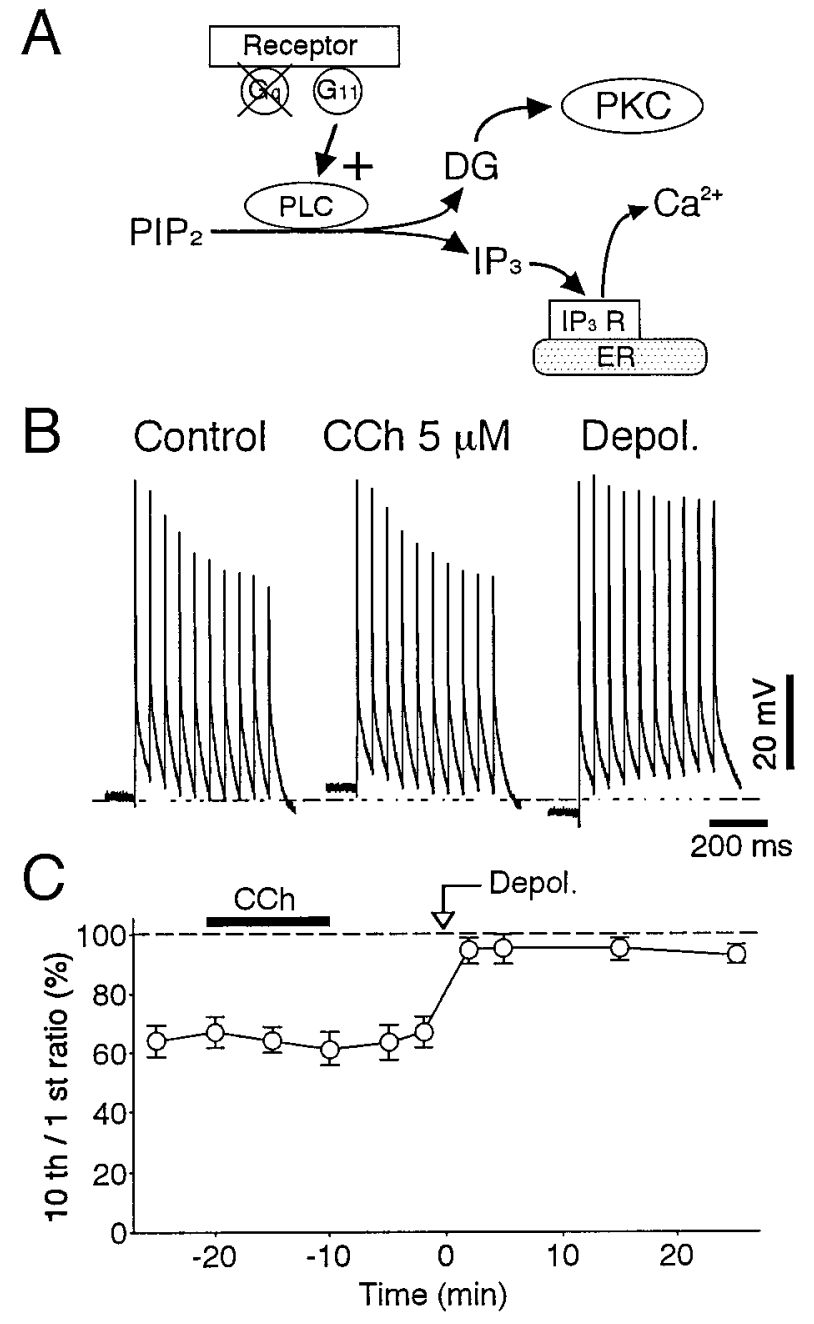

Figure 3. The $\mathrm{Ca}^{2+}$-induced facilitation is distinct from muscarinic modulation. $A$, Presumed intracellular cascade after M1 receptor activation in the $\mathrm{G}_{\mathrm{q}}$ knock-out mouse. $B$, Representative records from $\mathrm{G} \alpha_{\mathrm{q}}$ knock-out mice taken before (left), during bath application of CCh $5 \mu \mathrm{M}$ carbachol (middle), and after applying a depolarizing pulse train (right). Note that carbachol had no effect on dendritic spike modulation, whereas dendritic depolarization almost abolished the decrement of the spike amplitude. Broken lines indicate the levels of resting membrane potential at the control records. $C$, Time course of the change in decrement profiles in mutant CA1 neurons $(n=9)$. Bar $(C C h)$ indicates period of carbachol $(5 \mu \mathrm{M})$ application. Depolarizing currents were injected at time 0 (Depol.). 


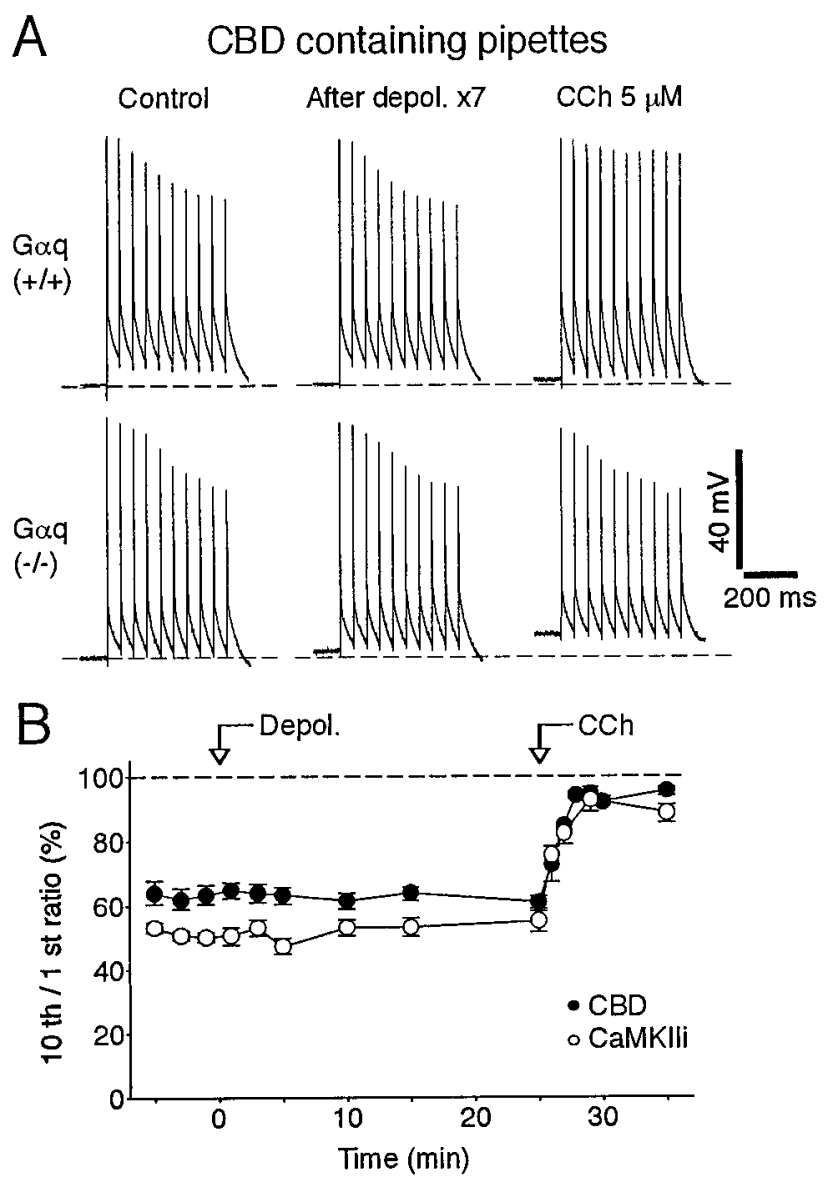

Figure 4. Involvement of CaMKII in the $\mathrm{Ca}^{2+}$-induced facilitation. $A$, Peptide inhibitors of CaMKII abolish the depolarization-induced facilitation of spike backpropagation. Trains of antidromic action potentials recorded from middle apical dendrites $(\sim 100 \mu \mathrm{m}$ from the soma) of wild-type $\left(\mathrm{G} \alpha_{\mathrm{q}}+/+\right.$, top traces $)$ and mutant $\left(\mathrm{G} \alpha_{\mathrm{q}}-/-\right.$, bottom traces $)$ cells with CBD-containing pipettes. Records were taken before (left) and $7 \mathrm{~min}$ after depolarizing trains (middle) and then during bath application of 5 $\mu \mathrm{M}$ CCh (right). Broken lines indicate levels of resting membrane potential at the control records. $B$, Time course of the change in decrement profiles in wild-type cells recorded with the pipette solution containing CBD (100 $\mu \mathrm{M})$ ( filled circles; $n=9$ ) or CaMKII inhibitor $(10 \mu \mathrm{M})($ CaMKIIi, open circles; $n=6$ ). Depolarizing pulses were delivered at time 0 , and CCh was applied to the bath at $25 \mathrm{~min}$.

receptor activation does not appear to trigger the downstream intracellular cascade properly (Fig. $3 A$ ). We then examined whether the depolarization-induced facilitation of spike backpropagation is present in $\mathrm{G} \alpha_{\mathrm{q}}$ knock-out mice. In a representative CA1 neuron from a $\mathrm{G} \alpha_{\mathrm{q}}$ knock-out mouse (Fig. 3B), a recording was made from the apical dendrite $100 \mu \mathrm{m}$ from the soma. During a train of antidromic action potentials, the amplitudes of later spikes were reduced (Control). These profiles did not change significantly in the presence of $5 \mu \mathrm{M}$ carbachol (CCh $5 \mu \mathrm{M})$, an M1 agonist. However, depolarizing current pulses (0.8 nA, $500 \mathrm{msec}$, five times) injected through the recording pipette induced a long-lasting reduction of the amplitude modulation (Depol.) of antidromic spike train. Time-dependent changes in decrement profiles obtained from nine different cells were summarized in Figure $3 C$. CCh had no effect on the decrement profiles, whereas injection of depolarizing pulses quickly reversed the amplitude modulation in all cells tested. These results suggest that the depolarization-induced facilitation of spike backpropagation in
A
$\mathrm{KN}-9310 \mu \mathrm{M}$
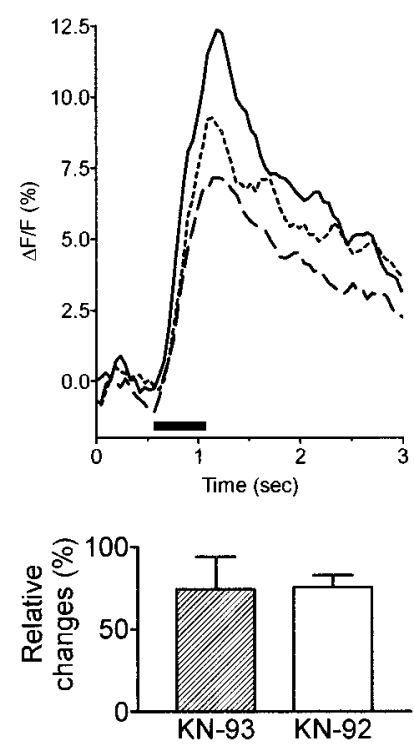

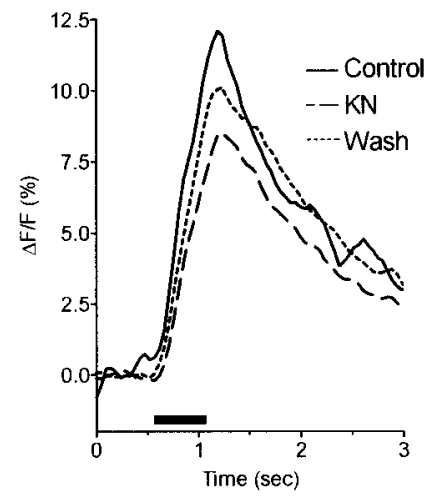

$\mathrm{KN}-9210 \mu \mathrm{M}$

B

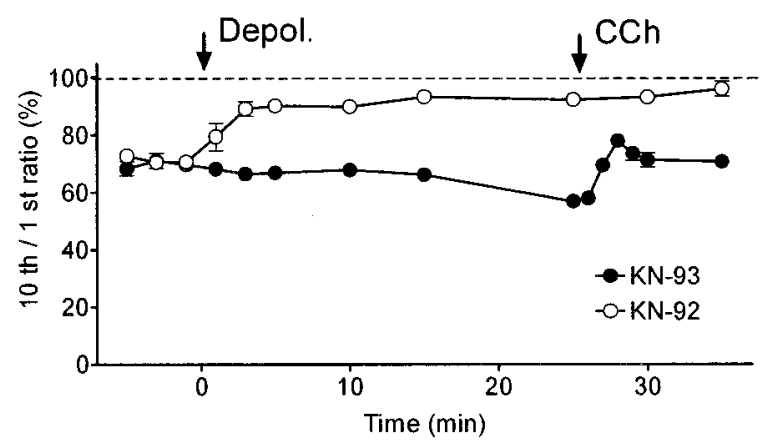

Figure 5. Effect of $\mathrm{KN}-93$ and $\mathrm{KN}-92$ on $\mathrm{Ca}^{2+}$ transients and the $\mathrm{Ca}^{2+}$-induced facilitation. $A$, Changes in $\left[\mathrm{Ca}^{2+}\right]_{\mathrm{i}}$ transients recorded from the soma in the presence of membrane-permeable CaMKII inhibitors KN-93 (top left) and its inactive isomer KN-92 (top right). Changes in fluorescence of bis-fura- 2 in response to somatic depolarization $(0.4$ $\mathrm{nA}, 500 \mathrm{msec}$ ) were measured at somatic region of CA1 pyramidal neurons in control (solid line), $10 \mathrm{~min}$ after application of inhibitors (broken line), and after wash out (dotted line). Data were obtained from two different cells. Periods of depolarization were indicated by a solid bar in each graph. Each trace was an average of two consecutive trials. Relative changes in peak fluorescence $(10-90 \%)$ in the presence of inhibitors were summarized (bottom bar graph; $74.5 \pm 19.5 \%$ for $\mathrm{KN}-93, n=5 ; 75.7 \pm$ $7.0 \%$ for KN-92, $n=5$ ). There was no significant difference (Student's $t$ test) between the two groups. $B$, Time course of the change in decrement profiles in cells in the bath solution containing $10 \mu \mathrm{M} \mathrm{KN}-93$ ( filled circles; $n=6$ ) and in that containing $10 \mu \mathrm{M} \mathrm{KN}-92$ (open circles; $n=6$ ). Depolarizing pulses were delivered at time 0 , and CCh was applied to the bath at $25 \mathrm{~min}$.

CA1 cells is dependent on $\mathrm{Ca}^{2+}$-dependent pathways other than those involving $\mathrm{M} 1$ and $\mathrm{G}_{\mathrm{q}}$.

Elevation of $\mathrm{Ca}^{2+}$ is known to activate $\mathrm{Ca}^{2+} / \mathrm{CaMKII}$ in various neurons, including hippocampal pyramidal cells (Scholz and Palfrey, 1998) and cerebellar Purkinje cells (Kano et al., 1996). We thus examined whether CaMKII is involved in the depolarization-induced facilitation of spike backpropagation. When the pipette contained $100 \mu \mathrm{M}$ CBD, a CaMKII inhibitor, depolarization-induced facilitation was abolished in the $\mathrm{G}_{\mathrm{q}} \mathrm{mu}$ tant $\left(\mathrm{G} \alpha_{\mathrm{q}}-/-\right)$ mice and their littermates $\left(\mathrm{G} \alpha_{\mathrm{q}}+/+, \mathrm{G} \alpha_{\mathrm{q}}+/-\right)$ 
(Fig. 4). Activity-dependent spike modulation was observed in CA1 neurons from both genotypes when recordings were made from middle apical dendrites $100 \mu \mathrm{m}$ from the soma. Even after several trains of depolarizing current injection, however, the amplitude modulation of antidromic spikes remained unchanged (Fig. 4A, $B$ ), suggesting that depolarization-induced facilitation of spike backpropagation requires activation of $\mathrm{Ca}^{2+} /$ calmodulindependent protein kinases. In the presence of $5 \mu \mathrm{M} \mathrm{CCh}$, facilitation of backpropagation occurred in the wild-type but not in $\mathrm{G}_{\mathrm{q}}$ mutant mice (Fig. 4A), indicating that the $\mathrm{M} 1-\mathrm{G}_{\mathrm{q}}$-dependent systems and the $\mathrm{Ca}^{2+} /$ calmodulin-dependent systems independently regulate the active spike backpropagation. Similar results were obtained when $10 \mu \mathrm{M} \mathrm{Ca}^{2+} / \mathrm{Calmodulin-kinase} \mathrm{II} \mathrm{inhibitor}$ 281-301 was contained in the pipette (Fig. 4B), suggesting that these inhibitory effects were attributable to blockade of CaMKII activities. We also tested effects of the membrane-permeable CaMKII inhibitor KN-93 (10 $\mu \mathrm{M})$ and its inactive isomer KN-92 $(10 \mu \mathrm{M})$. Because it is reported that some $\mathrm{KN}$-compounds block $\mathrm{Ca}^{2+}$ influx by means of a direct interaction with $\mathrm{Ca}^{2+}$ channels (Li et al., 1992; Maurer et al., 1996; Tsutsui et al., 1996; T. OhnoShosaku, personal communication), their application may reduce activity-dependent modulation of spike backpropagation regardless of CaMKII activity. Therefore, we measured changes in the depolarization-induced $\mathrm{Ca}^{2+}$ transient at the soma in the presence of KN-93 or KN-92 by using high-speed fluorescence imaging (Fig. $5 A$ ). Cells were filled with $50 \mu \mathrm{M}$ bis-fura- 2 dissolved in pipette solution. Depolarizing current pulses $(0.4 \mathrm{nA}, 500 \mathrm{msec})$ were injected through the somatic patch pipette, and timedependent changes in fluorescence were measured at somatic regions. During application of KN compounds (10 min after start of application), peak fluorescence changes were reduced in both cases $(74.5 \pm 19.5 \%$ for KN-93, $n=5 ; 75.7 \pm 7.0 \%$ for $\mathrm{KN}-92$, $n=5)$. Because there were no significant differences in each reduction rate, we assumed that both drugs blocked $\mathrm{Ca}^{2+}$ increases in a similar manner. However, bath application of $\mathrm{KN}-93$, but not KN-92, blocked the depolarization-induced enhancement. Time courses of decrement profile in both cases were shown in Figure $5 B$. CCh $(5 \mu \mathrm{M})$ was effective on the spike amplitude modulation in the presence of KN-93. Together, these results indicate that inhibition of the CaMKII activity blocked the long-lasting facilitation of spike backpropagation but did not affect the $\mathrm{G}_{\mathrm{q}}$-protein-dependent facilitation by muscarinic activation.

\section{DISCUSSION}

In the present study, we demonstrated that transient depolarization induced long-lasting facilitation of spike backpropagation in the apical dendrites of mouse CA1 pyramidal neurons. This effect was $\mathrm{Ca}^{2+}$-dependent and required an activation of CaMKIIdependent pathways. Depolarization-induced facilitation persisted in $\mathrm{G}_{\mathrm{q}}$ mutant mice in which $\mathrm{CCh}$ did not affect spike backpropagation, and conversely, CCh-induced facilitation was not affected by the CaMKII inhibitors. Therefore, it is suggested that the $\mathrm{Ca}^{2+} /$ calmodulin system modulates dendritic functions independently of the $\mathrm{G}_{\mathrm{q}}$-protein-coupled system. Our findings have revealed a new aspect of the intracellular mechanisms for controlling dendritic excitability.

\section{Intracellular control of excitability in the dendrites}

We have demonstrated that dendritic depolarizations enhance spike backpropagation in a manner similar to the muscarinic modulation we reported previously (Tsubokawa and Ross, 1997).
Because application of carbachol had no effects on the spike amplitude in the Gq-protein mutant mice (Tsubokawa et al., 1998), activation of the PKC-dependent pathways was suggested to be primarily responsible for the muscarinic facilitation. However, application of a PKC inhibitor $\mathrm{H}-7$ did not block the carbachol effect, although PKC-dependent facilitation caused by phorbol ester was completely abolished (Tsubokawa et al., 1999). Trains of action potentials used in the present study induced a dendritic $\mathrm{Ca}^{2+}$ influx that may be large enough to activate CaMKII. Moreover, activation of the intracellular $\mathrm{Ca}^{2+}$ regulatory mechanisms, such as $\mathrm{Ca}^{2+}$-induced $\mathrm{Ca}^{2+}$ release, can increase $\mathrm{Ca}^{2+}$ transients (Sandler and Barbara, 1999). It is likely that activation of muscarinic receptors can drive not only the PKC cascade through $\mathrm{G}_{\mathrm{q} / 11}$-protein but also $\mathrm{Ca}^{2+} / \mathrm{CaM}$ dependent system through $\mathrm{Ca}^{2+}$ mobilization from the internal stores. Similar phenomena have been reported for activation of $\mathrm{Ca}^{2+}$-activated $\mathrm{K}^{+}$conductances in hippocampal neurons. Muller et al. (1992) showed that muscarinic block of the afterhyperpolarization was abolished by a CaMKII inhibitor. This suggests intrinsic activation of CaMKII pathways after spiking that contributes to the muscarinic block. Engisch et al. (1996) also showed that bath application of $\mathrm{H}-7$ had no effect on inhibition of $I_{\mathrm{AHP}}$ by carbachol, although $\mathrm{H}-7$ reduced inhibition of $I_{\mathrm{AHP}}$ by a phorbol ester. These lines of evidence support the view that both the G-protein-coupled system and the $\mathrm{Ca}^{2+} / \mathrm{CaM}$ system contribute excitability control of the neuron in a combinatory manner.

\section{Cross talk between metabotropic pathways}

Our present results show that depolarization-induced facilitation of the dendritic spike propagation is quite similar to the facilitation caused by muscarine in terms of changes in amplitude modulation in a train. We have reported previously that the muscarinic modulation involves PKC activation (Tsubokawa et al., 1999). A contribution of PKC and/or PKA has been shown in the modulation of dendritic ionic conductances (for review, see Johnston et al., 1999). However, intracellular mechanisms that regulate those channel conductances do not seem to be simple in physiological conditions. Colbert and Johnston (1998) reported that pharmacological activation of PKC reversibly abolished frequency-dependent modulation of backpropagating $\mathrm{Na}^{+}$ spikes, presumably by decreasing slow $\mathrm{Na}^{+}$channel inactivation. In contrast, several other studies showed that activation of PKC decreases peak $\mathrm{Na}^{+}$current and slows its inactivation in the somata of hippocampal neurons (Numann et al., 1991; Li et al., 1993; Cantrell et al., 1996). It has also been reported that transient $\mathrm{K}^{+}$channels in dendrites, including A-type channels, are inhibited by pharmacological activation of PKC and PKA, and their inhibition increases dendritic spike amplitudes to the levels seen at the soma (Hoffman and Johnston, 1998). However, with low $\mathrm{Ca}^{2+}$ extracellular solution (nominally $0 \mathrm{mM}$ ) decrement of the spike amplitude in a train remained even in the presence of high concentration of 4-AP (Tsubokawa et al., 1998). Therefore, at least contribution of the A-type $\mathrm{K}^{+}$channels to the activitydependent modulation might be small. A possible reason for these complex results would be that PKC and/or PKA seem to affect not only their own substrates directly but also other intracellular cascades indirectly. One of the likely candidates for interaction with the PKC-dependent pathways would be the $\mathrm{Ca}^{2+} /$ calmodulin system because PKC and $\mathrm{Ca}^{2+} /$ calmodulin share the same substrate domains (for review, see Chakravarthy et al., 1999). Pharmacological activation of one of these kinases may induce combined effects by cross talk of their intracellular cascades. 


\section{Roles of dendritic action potentials}

The physiological significance of spike backpropagation is not yet clear. Large dendritic $\mathrm{Na}^{+}$spikes were not observed in layer II/III pyramidal cells of the anesthetized rat somatosensory cortex in vivo (Svoboda et al., 1997, 1999). On the other hand, large amplitude fast spikes in dendrites occur during population discharge in CA3 and CA1 neurons in the intact rat hippocampus (Kamondi et al., 1998). For the induction of long-term potentiation (LTP), antidromic invasion of $\mathrm{Na}^{+}$spikes are suggested to be required in the rat CA1 pyramidal neurons (Magee and Johnston, 1997). These spikes induce large $\mathrm{Ca}^{2+}$ influxes in the dendrites through the voltage-dependent $\mathrm{Ca}^{2+}$ channels (Markram et al., 1995; Spruston et al., 1995). A recent report by Nakamura et al. (1999) clearly demonstrated that large $\mathrm{Ca}^{2+}$ releases from the internal stores were induced at the dendrites when metabotropic glutamate receptors are activated synergically with backpropagating spikes. This $\mathrm{Ca}^{2+}$ signaling may contribute activation of $\mathrm{Ca}^{2+}$-dependent enzymes such as PKC, PKA, and CaMKII. Accumulating evidence suggests that CaMKII plays a key role in LTP induction in the CA1 area of the hippocampus (Silva et al., 1992a,b; Lisman, 1994; Otmakhov et al., 1997; Nicoll and Malenka, 1999; Ouyang et al., 1999). A recent report showing that endogenous CaMKII induces morphological stabilization of the dendritic arbor during neuronal maturation (Wu and Cline, 1998) also supports the idea that activity of the $\mathrm{Ca}^{2+} /$ calmodulin system is responsible for a long-term change in the dendrites. In the present study, we demonstrate a new role of the $\mathrm{Ca}^{2+} /$ calmodulin system in the regulation of dendritic excitability that may influence LTP induction significantly. Depolarization-induced facilitation of dendritic spike backpropagation results in an enhancement of $\mathrm{Ca}^{2+}$ entry into the dendrite during tetanus, which may in tern cause facilitation of CaMKII activation and LTP induction.

\section{REFERENCES}

Adams JP, Anderson AE, Johnston D, Pfaffinger PJ, Sweatt JD (1997) Kv4.2: a novel substrate for MAP kinase phosphorylation. Soc Neurosci Abstr 23:1176.

Callaway JC, Ross WN (1995) Frequency dependent propagation of sodium action potentials in dendrites of hippocampal CA1 pyramidal neurons. J Neurophysiol 74:1395-1403.

Cantrell AR, Ma JY, Scheuer T, Catterall WA (1996) Muscarinic modulation of sodium current by activation of protein kinase $\mathrm{C}$ in rat hippocampal neurons. Neuron 16:1019-1026.

Chakravarthy B, Morley P, Whitfield J (1999) $\mathrm{Ca}^{2+}$-calmodulin and protein kinase Cs: a hypothetical synthesis of their conflicting convergences on shared substrate domains. Trends Neurosci 22:12-16.

Colbert CM, Johnston D (1998) Protein kinase C activation decreases activity-dependent attenuation of dendritic $\mathrm{Na}^{+}$current in hippocampal CA1 pyramidal neurons. J Neurophysiol 79:491-495.

Colbert CM, Magee JC, Hoffman DA, Johnston D (1997) Slow recovery from inactivation of $\mathrm{Na}^{+}$channels underlies the activity-dependent attenuation of dendritic action potentials in hippocampal CA1 pyramidal neurons. J Neurosci 17:6512-6521.

Engisch KL, Wagner JJ, Alger BE (1996) Whole-cell voltage-clamp investigation of the role of $\mathrm{PKC}$ in muscarinic inhibition of $\mathrm{I}_{\mathrm{AHP}}$ in rat CA1 hippocampal neurons. Hippocampus 6:183-191.

Hill B (1994) Modulation of ion-channel function by G-protein-coupled receptors. Trends Neurosci 17:531-536.

Hoffman DA, Johnston D (1998) Downregulation of transient $\mathrm{K}^{+}$channels in dendrites of hippocampal CA1 pyramidal neurons by activation of PKA and PKC. J Neurosci 18:3521-3528.

Hoffman DA, Magee JC, Colbert CM, Johnston D (1997) $\mathrm{K}^{+}$channel regulation of signal propagation in dendrites of hippocampal pyramidal neurons. Nature 387:869-875.

Johnston D, Magee JC, Colbert CM, Cristie BR (1996) Active properties of neuronal dendrites. Annu Rev Neurosci 19:165-186.
Johnston D, Hoffman DA, Colbert CM, Magee JC (1999) Regulation of back-propagating action potentials in hippocampal neurons. Curr Neurobiol 9:288-292.

Jung H, Mickus T, Spruston N (1997) Prolonged sodium channel inactivation contributes to dendritic action potential attenuation in hippocampal pyramidal neurons. J Neurosci 17:6639-6646.

Kamondi A, Acsady L, Buzsaki G (1998) Dendritic spikes are enhanced by cooperative network activity in the intact hippocampus. J Neurosci 18:3919-3928.

Kano M, Kano M, Fukunaga K, Konnerth A (1996) $\mathrm{Ca}^{2+}$-induced rebound potentiation of $\gamma$-aminobutyric acid-mediated currents requires activation of $\mathrm{Ca}^{2+} /$ calmodulin-dependent kinase II. Proc Natl Acad Sci USA 93:13351-13356.

Li G, Hidaka H, Wolheim CB (1992) Inhibition of voltage-gated $\mathrm{Ca}^{2+}$ channels and insulin secretion in HIT cells by the $\mathrm{Ca}^{2+} /$ calmodulindependent protein kinase II inhibitor KN-62: comparison with antagonists of calmodulin and L-type $\mathrm{Ca}^{2+}$ channels. Mol Pharmacol 42:489-498.

Li M, West JW, Numann R, Murphy BJ, Scheuer T, Catterall WA (1993) Convergent regulation of sodium channels by protein kinase $\mathrm{C}$ and cAMP-dependent protein kinase. Science 261:1439-1442.

Lisman J (1994) The CaM kinase II hypothesis for the storage of synaptic memory. Trends Neurosci 17:406-412.

Magee JC (1998) Dendritic hyperpolarization-activated currents modify the integrative properties of hippocampal CA1 pyramidal neurons. J Neurosci 18:7613-7624.

Magee JC, Johnston D (1997) A synaptically controlled, associated signal for hebbian plasticity in hippocampal neurons. Science 275:209-213.

Markram H, Helm PJ, Sakmann B (1995) Dendritic calcium transients evoked by single back-propagating action potentials in rat neocortical pyramidal neurons. J Physiol (Lond) 485:1-20.

Maurer JA, Wenger BW, McKay DB (1996) Effects of protein kinase inhibitors on morphology and function of cultured bovine adrenal chromaffin cells: KN-62 inhibits secretory function by blocking stimulated $\mathrm{Ca}^{2+}$ entry. J Neurochem 66:105-113.

Mittmann T, Linton SM, Schwindt P, Crill W (1997) Evidence for persistent $\mathrm{Na}^{+}$current in apical dendrites of rat neocortical neurons from imaging of $\mathrm{Na}^{+}$-sensitive dye. J Neurophysiol 78:1188-1192.

Muller W, Petrozzino JJ, Griffith LC, Danho W, Conner JA (1992) Specific involvement of $\mathrm{Ca}^{2+}$-calmodulin kinase II in cholinergic modulation of neuronal responsiveness. J Neurophysiol 68:2264-2269.

Nakamura T, Barbara JG, Nakamura K, Ross WN (1999) Synergistic release of $\mathrm{Ca}^{2+}$ from IP3-sensitive stores evoked by synaptic activation of mGluRs paired with backpropagating action potentials. Neuron 24:727-737.

Nicoll RA, Malenka RC (1999) Expression mechanisms underlying NMDA receptor-dependent long-term potentiation. Ann NY Acad Sci 868:515-525.

Numann R, Catterall WA, Scheuer T (1991) Functional modulation of brain sodium channels by protein kinase $\mathrm{C}$ phosphorylation. Science 254:115-118.

Otmakhov N, Griffith LC, Lisman JE (1997) Postsynaptic inhibitors of calcium/calmodulin-dependent protein kinase type II block induction but not maintenance of pairing-induced long-term potentiation. J Neurosci 17:5357-5365.

Ouyang Y, Rosenstein A, Kreiman G, Schuman EM, Kennedy MB (1999) Tetanic stimulation leads to increased accumulation of $\mathrm{Ca}^{2+} /$ calmodulin protein kinase II via dendritic protein synthesis in hippocampal neurons. J Neurosci 19:7823-7833.

Sandler VM, Barbara JG (1999) Calcium-induced calcium release contributes to action potential-evoked calcium transients in hippocampal CA1 pyramidal neurons. J Neurosci 19:4325-4336.

Scholz WK, Palfrey HC (1998) Activation of $\mathrm{Ca}^{2+} /$ calmodulindependent protein kinase II by extracellular calcium in cultured hippocampal pyramidal neurons. J Neurochem 71:580-591.

Silva AJ, Stevens CF, Tonegawa S, Wang Y (1992a) Deficient hippocampal long-term potentiation in $\alpha$-calcium-calmodulin kinase II mutant mice. Science 257:201-206.

Silva AJ, Paylor R, Wehner JM, Tonegawa S (1992b) Impaired spatial learning in $\alpha$-calcium-calmodulin kinase II mutant mice. Science 257:206-209.

Spruston N, Schiller Y, Stuart G, Sakmann B (1995) Activity-dependent action potential invasion and calcium influx into hippocampal CA1 dendrites. Science 268:297-300. 
Stuart G, Sakmann B (1994) Active propagation of somatic action potentials into neocortical pyramidal cell dendrites. Nature 367:69-72.

Stuart G, Spruston N (1998) Determinants of voltage attenuation in neocortical pyramidal neuron dendrites. J Neurosci 18:3501-3510.

Svoboda K, Denk W, Kleinfeld D, Tank DW (1997) In vivo dendritic calcium dynamics in neocortical pyramidal neurons. Nature 385:161-165.

Svoboda K, Helmchen F, Denk W, Tank DW (1999) Spread of dendritic excitation in layer $2 / 3$ pyramidal neurons in rat barrel cortex in vivo. Nat Neurosci 2:65-73.

Takigawa T, Alzheimer C (1999) G protein-coupled inwardly rectifying $\mathrm{K}^{+}$(GIRK) currents in dendrites of rat neocortical pyramidal cells. J Physiol (Lond) 517:385-390.

Tsubokawa H, Ross WN (1997) Muscarinic modulation of spike backpropagation in the apical dendrites of hippocampal CA1 pyramidal neurons. J Neurosci 17:5782-5791.

Tsubokawa H, Offermanns S, Simon M, Kano M (1998) Dendritic depolarization induces long-lasting enhancement of spike backpropagation in the apical dendrites of CA1 pyramidal neurons. Soc Neurosci Abstr 24:2018.
Tsubokawa H, Miura M, Kano M (1999a) Elevation of intracellular $\mathrm{Na}^{+}$ induced by hyperpolarization at the dendrites of pyramidal neurons of mouse hippocampus. J Physiol (Lond) 517:135-142.

Tsubokawa H, Kawai N, Ross WN (1999b) Muscarinic modulation of $\mathrm{Na}^{+}$spike propagation in the apical dendrites of hippocampal CA1 pyramidal neurons. In: Slow synaptic responses and modulation (Kuba K, Higashida H, Brown DA, Yoshioka T, eds.), pp. 416-419. Tokyo: Springer Tokyo.

Tsutsui M, Yanagihara N, Fukunaga K, Minami K, Nakashima Y, Kuroiwa A, Miyamoto E, Izumi F (1996) $\mathrm{Ca}^{2+} /$ calmodulin-dependent protein kinase II inhibitor $\mathrm{KN}-62$ inhibits adrenal medullary chromaffin cell functions independent of its action on kinase. J Neurochem 66:2517-2522.

Turner RW, Meyers DER, Richardson TL, Barker JL (1991) The site for initiation of action potential discharge over the somatodendritic axis of rat hippocampal CA1 pyramidal neurons. J Neurosci 11:2270-2280.

Wu GY, Cline HT (1998) Stabilization of dendritic arbor structure in vivo by CaMKII. Science 279:222-226. 